\title{
13 Place-based approach and family firms
}

\author{
The Tatula Programme in \\ Lithuania
}

Rodrigo Basco and Inga Bartkevičiūtè

\section{Introduction}

The process of globalisation has brought benefits for less developed regions and enabled them to become a part of the broader systems of production, distribution, and consumption. However, globalisation per se does not reduce the inequality gap among regions. Although some regions have benefited from the opportunities arising from it, in general, social and geographical polarisation has increased (Pike, Rodríguez-Pose, \& Tomaney, 2006); that is, most regions around the world are struggling to identify and utilise their potential to be part of the globalisation process.

Throughout this process, policymakers have tried to understand and correct the inequality gap. They have implemented, with different degrees of success, specific actions to overcome the problems due to which regions miss the benefits of globalisation, by using the traditional approach rooted in the classical economic growth theories. These strategies were traditionally designed to tackle regional disparities by applying the so-called 'topdown' approach, that is, national governance institutions played a critical role in developing strategies. Top-down strategies tend to focus on deficiencies associated with a region's economic problems, applying a universal approach to tackle these problems, regardless of the local context. However, such traditional regional development solutions have been only partially successful, encouraging academia and policymakers to rethink the concepts of regional development.

Since the late 1990s, the place-based approach to economic development has been related to a more holistic interpretation of the causes and consequences of local and regional economic development. During this time, local and regional economic development theories and practices have witnessed a shift from a firm-oriented sectoral approach towards a more in-depth consideration of unique local factors, resources, and actors (Rogerson \& Rogerson, 2010), recognising the importance of bottom-up actions characterised by comprehensive analysis of regional micro-foundations. This change in approach to local and regional development was also prompted by the process of decentralisation and the growing empowerment of sub-national governments all over the world (Rodríguez-Pose \& Wilkie, 2017). 
Even though important theoretical and practical advances have been made in framing and understanding the place-based approach - within the micro-foundations perspective that accounts for local socioeconomic actors and the participative processes to create and implement actions aimed at energising less developed geographical areas or regions-local family firms have received less academic attention (Basco \& Bartkevičiūtè, 2016). More specifically, the importance of local family firms as a node in the relational space has not been recognised. Therefore, this chapter aims to explore the role that local family firms may play when place-based approach initiatives are implemented in lagging regions. We present, explore, and analyse the case study of the Tatula Programme in Lithuania.

We can summarise our results as three important characteristics of family firms for place-based approach. First, the entrepreneurial orientation of family firms leverages place-based programme actions by using existing local knowledge to reconfigure resources in different and innovative ways. Second, the long-lasting embeddedness of family firms, characterised by their social capital, embraces other socioeconomic actors in their initiatives to unfold a participative developmental approach. Finally, the connection between family firms and their territory creates a sense of belonging to generate the intention to stay in the region, favouring local action in the long term. This chapter contributes to both theory and practices. We expect that this exploratory case study will open the door to better understanding the micro-foundations of place-based approach as a lens to promote regional socioeconomic development. Additionally, the case study that we present highlights practical contributions by illustrating the importance of encouraging local actors - in this case, family firms - to create long-lasting conditions that boost economic dynamism.

\section{Framework}

\section{Traditional approach}

One of the main challenges for policymakers in terms of regional development is to tackle economic disparities between different regions. Economic growth theories and some policies, in the second part of the 20th century, were dominated by a macroeconomic approach (Scott \& Storper, 2003; Vasquez-Barquero, 2010) and designed for national income growth (Vasquez-Barquero, 2010). Traditional policies to reduce the inequality gap between leading and lagging areas were designed and implemented by applying a top-down approach. Such top-down strategies tended to tackle the most important development shortcoming that was seen as the main impediment for economic development, thus ignoring other relevant factors (Pike et al., 2006) such as local culture, human resources, or technological context. These policies aimed at reducing location deficiencies by replicating the regional development path of now-developed regions. Most strategies focused on infrastructural investments to build highways, railways, and 
telephone lines, and on attracting large manufacturing companies to less developed areas (Pike et al., 2006). However, this approach did not produce the expected results of diminishing regional inequalities.

Since the 1960s, the regional planning policy framework in various countries (e.g., Italy and France) has been highly affected by well-known growth poles theory (Perroux, 1955), which suggests that a growth pole is formed by a group of industries connected through input-output linkages. Although the original theory is not related to a particular geographical space (especially one that is characterised as a country with its regions), and defines growth pole as an economic category, other scholars proposed regional implications of the growth poles theory. Boudeville (1966) transformed the idea of a growth pole in terms of place and suggested the concept of geographic clustering of economic activity. In practical application, growth poles were treated as urban centres with the anticipation that an industrialised area will also stimulate the development of adjacent regions. Specifically, during the 1960s and 1970s (Higgins \& Savoie, 1988), this approach manifested mainly as an attraction of industrial firms to urban centres located in lagging regions. Most of the strategies dealing with regional development were designed at the national level and had a tendency to be replicated across different regional contexts.

The implementation of regional development policies based on poles brought some positive impact on the reduction of regional disparities, as it contributed to an increase in employment and income (Vasquez-Barquero, 1999). However, the critical question lies in the sustainability of the generated impact, that is, to what extent the policies induced self-sustained local development.

An interesting example is the long-lasting effort to reduce differences in development between the southern and northern parts of Italy. Following the growth pole theory and the related approaches, a strategy to tackle the problems of underdeveloped southern Italy (Mezzogiorno) was implemented during the 1950s-1980s. Various locations in the region were designated as growth centres, to establish big state-controlled industrial firms and to attract smaller firms that would supply goods and services to the local market. (Pacione, 1982). However, these massive plants did not embed into the local context, which was characterised by weak endogenous industrial structures and was missing industrial networks that would foster sustainable local development and employment. Therefore, these plants became 'cathedrals in the desert' as most suppliers and consumers were not located in the vicinity (Trigilia, 2012).

Even though one of the problems in the Mezzogiorno intervention can be related to the loss of effectiveness during the implementation phase (Felice \& Lepore, 2017), the leading causes of the failure seemed to point at insufficient attention given to the local cultural, social, and economic context. For instance, in the context of an agricultural region, investments were designed to develop large and capital intensive industries. It created tensions at the 
very beginning of policy implementation because of the radical transition from an agricultural to an industrial economy. Even more, one of the major difficulties was the takeover of agricultural land — which may have belonged to a farmer's family for several generations - for industrial use (Pacione, 1982). Additionally, the newly established factories lacked skilled workers as regional human capital did not embody the required specific knowledge, culture, and other attributes associated with the new industries.

The main limitation of the top-down approach and the universal regional development strategy is its spatial-blindness. This can be seen as one of the reasons why the practical application of standardised development policies in different conditions seldom generate the anticipated impact on sustainable long-term economic development (Storper, 1997) and have even created adverse effects (Pike et al., 2006). A lack of proper evaluation of the local context in many cases has led to the jeopardising of local entrepreneurial resources and local firms that were not able to compete with major industrial players attracted to the region (Vasquez-Barquero, 1999). Although it was expected that non-local, large, and technologically advanced firms relocated in less developed areas may induce local business development by generating new linkages, thereby triggering entrepreneurship, and expanding knowledge spill-overs, this was not always the case. In most cases, new firms relocated in less developed areas exploited the lagging regions simply as new labour supply markets (Pike et al., 2006).

\section{Place-based approach}

The aforementioned lack of success in strategies to reduce inequality among regions prompted new discussions in the regional development field during the late 1990s, offering greater impetus to explore alternative dimensions such as the location and its cultural, economic, institutional, technological, and political contexts. The fact that not all regions developed and innovated at the same pace raises a question about something underneath traditional developmental policies that either boosts or hinders prosperity. Thus, the idea that regional development today should follow the patterns of now-developed countries and rely mostly on the development of mega-urban regions was questioned (Barca, McCann, \& Rodriguez-Pose, 2012). Although this approach is attractive - as it allows the building of universal development models looking at the experience of now-developed regions and locations, and analysing long-term dynamics of their development - the complete reliance on universally-presented tendencies carries a risk of misjudging the relationship between universal causes and local context (Storper, 2011).

What seems to be overlooked while promoting space-neutral interventions is the need to leverage local potential, which has become one of the main focuses of the place-based approach to regional development. This approach emphasises local potential and means to maximise it rather than only introducing universal economic growth solutions or simple administrative 
redistribution of wealth to achieve regional convergence. Thus, while the place with its characteristics is recognised as a factor in economic growth, the place-based approach considers it a relational one in which proximity has a meaning, not only in terms of geographical proximity but also in terms of institutional, cognitive, and organisational proximity.

Successful place-based policies cannot be written using a ready-made universal template. Instead, they should be developed in close cooperation with local and external actors, and identify and rely on locally embedded knowledge. Moreover, for example, policies aimed at increasing the local economy cannot merely tackle the competitiveness of local firms but should also evaluate all the contextual conditions, including human capital, physical infrastructure, and so on (Rodríguez-Pose \& Wilkie, 2017); that is, they should analyse the region holistically. As Rodríguez-Pose and Wilkie (2017) state, in terms of economic growth the question should be 'not if different localities have the potential to achieve sustainable and inclusive economic growth via territorial approaches to development, but rather, what must be done to ensure that they do, and relatedly, how do they do it'.

Consequently, the application of the place-based approach leads to a greater variety of regional development strategies (Rodríguez-Pose \& Wilkie, 2017), opening the door for more complex solutions that cannot be achieved in a simplified solution based on a 'one size fits all' approach (Barca et al., 2012). In practice, the interpretation of the place-based approach varies from government to government. As it does not have theoretical underpinning, its practical application depends highly on local context and traditions. For instance, the European Union (EU) document 'Territorial Agenda of the European Union 2020' calls for greater awareness of the territory and aims to unleash the local potential using location-specific assets and factors that contribute to the competitiveness of places. Following this approach, the European Commission uses dedicated instruments and requires member-states to develop bottom-up place-based strategies to receive funding under specific EU funding programmes, recognising the place-based approach as an essential tool in enhancing territorial cohesion. Although the general requirements for the implementation of place-based instruments are common to all countries, the adaptation of the framework in different member states and its sub-regions suggests a vast array of local strategic solutions (CSIL, 2015; BGI Consulting, 2019).

However, theory and practice suggest some universal attributes of all successful place-based strategies. As the place-based approach is associated with decentralisation and the empowerment of sub-national governments, one of the main preconditions for its successful application is the vertical and horizontal integration of institutions and social partners (Barca et al., 2012). Therefore, place-based policies should be built on cooperation among national, regional, and local governments, and with socioeconomic partners. 


\section{Local family firms in the place-based approach}

Place-based approach requires the local economic and social actors' involvement to develop actions within regional strategies. Their participation, engagement, and commitment are important characteristics to tailor actions that are going to affect their social and economic life. Endogenous actors are crucial contributors for developing, implementing, and evaluating regional strategies because they are the source of local knowledge. Moreover, they are part of the local social capital, which enhances strategic planning in terms of connections and networks. However, not all economic and social actors are the same and their contributions to successful design and implementation of regional strategies may depend on their specific attributes.

Family firms pose specific characteristics because of the active family participation in ownership, governance, and management decision-making. Because of this, family firms have a unique set of goals characterised by the coexistence of business- and family-oriented goals (Basco, 2017), altering the reference point for making decisions. For instance, while economic performance is an essential issue for any firm, family firms may accept lower expected economic performance at the expense of transferring the firm to next generation, to maintain the headquarters in their local territory or even to contribute and participate in the local and regional development through corporate local and regional responsibility actions (Lenz, 2020). In this sense, family firms become unique socioeconomic actors for policymakers to integrate into the debate on local socioeconomic development.

Local embeddedness of family firms could play an important role in applying the place-based approach for several reasons. First, family firms are guardians of local business culture, which could help interpret implicit codes of conduct, values, and beliefs when doing business. Second, family firms are important local nodes embedded in the socioeconomic network in the relational space through which information and knowledge flow. Finally, beyond the geographical proximity of family firms, they leverage other proximity dimensions such as organisational, social, and cognitive.

Even though family firms possess unique characteristics and a potential role in the local socioeconomic life, this specific local actor has not been theorised in the micro-foundations of the place-based approach. Considering that family firms are the most common form of organisation in the EU (Ricotta \& Basco, 2020), our research question is as follows:

What roles do family firms play in place-based approach intervention?

\section{The case study of the 'Tatula Programme'}

\section{Sustainable farming promotion in ecologically vulnerable regions}

The place-based approach can be applied in regional or local programmes varying in scale, topics, and policy instruments. Its main characteristic is 
that it does not have a clear and universal pattern in terms of suitable interventions; instead, its philosophy is to carefully examine local circumstances to develop actions and implement them by embracing local actors and using the potential of local regional factors and processes. We aim to describe and explore a small-scale development programme that shows how locally tailored actions can help foster empowerment and unlock local potential in outlying areas.

\section{Data}

We collected qualitative and quantitative data from different sources of information, such as the Lithuanian statistic office, the certification institution 'Ekoagros', legal documents, academic papers, and additional information available in the national and local media. We also interviewed the management of the Tatula programme. Additionally, we used our observations of the Tatula programme development. For instance, we actively participated in organic farms to observe the interaction and action among Tatula participants and their customers. As customers of some Tatula farmers, we have witnessed their development.

\section{The region}

Part of northern Lithuania is covered by karst landscape underlain by carbonate rocks (gypsum-dolomite). The dissolution of these soluble rocks produces underground drainage system with sinkholes. In karst landscapes, the precipitation infiltrates into aquifer not only through the soil, which acts as a natural filter against some contaminants, but also directly through karst sinkholes that could be covered only with a thin layer of soil. Moreover, as underground sinkholes are often interlinked with each other, contaminants spread faster. These features are of particular concern when land is intensively used for agriculture purposes, because fertilisers, pesticides, and oil products remain in surplus in groundwater. Karstic landscape covers around $10 \%$ of Lithuanian territory, of which almost 30,000 hectares are characterised by intensive karstic processes. The geographical area of the intensive karst process overlaps with two local administrative districts located in northern Lithuania, namely, Birzu and Pasvalio.

\section{The programme}

To reduce groundwater pollution, the first initiative to implement environmental measures and to transform agriculture practices in northern Lithuania was launched back in 1993. The programme adopted by the Lithuanian government aimed at reducing groundwater pollution in the designated areas. A significant part of the programme was dedicated to the promotion of sustainable farming in the Birzu and Pasvalio districts and was implemented under the title 'Tatula programme'. The Tatula programme 
provides membership to any sustainable farming or processing entity, although the majority of its members are family-owned farms.

Although the funding of the Tatula programme has undergone various stages since its launch, activities promoting sustainable farming in northern Lithuania under the Tatula programme continue until today. The initial programme, which was adopted in 1993, was supported by national funding until the end of the 1990s. This period was characterised by the highest financial allocations to support farmers' transition to sustainable farming practices, promote environmental monitoring in the region, and construct wastewater treatment plants. Since 2000, the national government's attention to the specific issues of the karst region has significantly diminished and various EU funds have emerged as the leading financial source for its implementation. In 2014, a new political initiative to revive the former strategy of environmental protection of vulnerable karst region was launched. Following it, in 2015, a national law on agriculture and rural development was supplemented by a new policy aimed at sustainable farming in northern Lithuania. Implementation of this policy is supported by triennial action plans (2016-2018 and 2019-2021), which include funds for Tatula programme activities.

\section{Governance}

The Tatula programme is designed at the national level. However, local actors and agriculture scientists have actively participated in tailoring the programme's actions. The responsibility for implementing the programme was assigned to the Tatula programme organisation, which is governed by a multilevel governance structure formed by regional and local economic, social, and political actors such as farmers, agricultural firms, scientists, local politicians, representatives of non-government organisations, and other regionally acclaimed people. Since its launch, the Tatula programme has been organised in a form similar to cooperative, that is, its members (local farmers) have a vote and actively participate in the programme's development. The number of Tatula programme members has fluctuated, reaching a peak in 2000 with around 150 active members. The members' local embeddedness and prior connections have helped build a strong network based on existing social capital. It has not only become the programme's support network but also serves as a local knowledge and resource exchange platform amongst farmers, boosting the programme's positive impact on the region.

\section{Programme's main activities}

The Birzu and Pasvalio districts are primarily dedicated to agriculture, which has been the main economic activity in the region. The vast majority of local agriculture entities were (are) small family-owned farms characterised by low business orientation. One specific attribute of the Tatula programme, since its inception, has been to consider soft aspects 
of socioeconomic development as well as existing local knowledge when transforming economic practices. Thus, it suggested a means to enhance particular economic activities built on long-lasting local experience, rather than the reverse socioeconomic structure of the region. The programme was specifically tailored to the needs of local natural conditions and economic activities.

The initial Tatula programme had a goal to convert $5 \%$ of all agricultural land in the two aforementioned districts into sustainable farming lands. It is important to highlight that in the 1990s, the practice of sustainable farming in Lithuania barely existed. Therefore, it was assumed that only the promotion of sustainable farming among local farmers through tax incentives, funding, or similar typical interventions would not be sufficient to achieve a long-term impact on farming practices. Consequently, along with subsidies for wastewater treatment facilities, soft loans for the development of agriculture business plans, and acquisition of equipment, among other classical instruments, the Tatula programme took a holistic perspective, including additional soft measures oriented to the particular needs of current and future farmers.

The programme began collaborating with agriculture scientists who were responsible for developing proposals on new farming practices, types of plants best suitable for the particular soil in these districts, use of organic fertilisers, and crop rotation. The programme funded the development of scientific recommendations directly related to the specificity characteristics of the karst region. Local farmers were also given multiple opportunities to directly consult with scientists specialising in karst landscape farming issues and to visit other farmers successfully applying particular methods. Importantly, the scientific recommendations in multiple cases were developed in close collaboration with local farmers, whose long-running experience in farming in the particular landscape enriched scientific approach with valuable pragmatic insights and increased its practical applicability.

Although the support for the development of new sustainable farming practices was an important aspect of the programme, another crucial issue was to induce the business orientation of small family-owned farms to convert their local agriculture practice into a viable economic activity. In this regard, the certification of sustainable agriculture farms and its production helped local farmers differentiate their products from agrochemical-based agriculture and access one specific consumer segment in the market. In this sense, the programme leveraged the local entrepreneurial orientation by converting family farms into family business farms.

The national organic certification system was introduced in 1997. However, Tatula's management and co-working scientists soon realised that for some farms, local organic certification was still too early and too complicated. The problem was attributed to the complex requirements that the owner of organic certification had to adopt and the complicated process, 
which could become a burden to small, mainly family-owned farms. Therefore, since 2003, the Tatula programme has started introducing a regional certification system. It is based on a ground analysis of the local farming conditions and promotes the so-called sustainable farming system. This new certification entails the use of progressive farming methods that are less environmentally harmful than traditional ones but are easier to implement than organic certification. Some farms participating in the Tatula programme were certified following the new system, even though the original sustainable farming certification system ceased to exist within a few years of its introduction.

Nevertheless, the system was beneficial to the region's environmental goals and organic agriculture businesses. It encouraged farms to progressively introduce less environmentally harmful farming practices and prepare themselves to turn their farms organic in the future. Additionally, this new alternative programme has opened several connections, support, and product distribution channels for farmers.

To ensure business continuity and new opportunities for farmers, the programme dedicated part of its resources to creating access to retail food markets. This initiative was important, particularly in the initial stages of the programme, because the regular sustainable farm-produce supply was insufficient and could not adapt to the conditions of big retail chains. Therefore, sales through farmer's markets were identified as the primary channel for creating business opportunities by meeting customers.

In the 1990s and early 2000s, the demand for organic food in Lithuania was low mainly because of a lack of awareness and the high price of organically grown products. The information regarding the characteristics of organic products and their benefits was scarce. The Tatula programme started organising and promoting farmers' markets under the Tatula brand in different locations of the country. Direct-to-consumer markets were seen as a good opportunity to create a new ecosystem of customers and farmers that understood each other in terms of needs and expectations. Although it began as occasional events, some locations have become meeting points where farmers and customers can interact regularly.

The Tatula programme employed various methods to encourage the link between farmers and customers. For instance, public funds were directed to cover farmers' participation expenses such as stall rent, market advertisements, and transportation costs. The transportation cost was introduced considering the geographical location of the target region and the distance from the capital, which is the leading market area for organic produce. Moreover, the Tatula programme actively promoted sustainable farming production on local and national media and, thus, made the Tatula brand visible. The programme's farmers have benefited from it and the 'Tatula programme' has become recognisable as a brand representing assured quality. 
Some of the aforementioned activities of the Tatula programme continue today. Currently, public funds are used to further organise farmer markets, support new training programmes for organic farms, develop new organic products, and raise public awareness regarding multiple benefits of organic production. Additionally, the programme has increased its efforts in promoting farm-based processing of primary agriculture products and their certification.

\section{Impact}

In Lithuania, organic farming barely existed in the 1990s. The volume of organic farming commenced gradual growth only in the late 1990s after the national certification agency was established and national organic farming support payments were introduced. By 2002, only $0.3 \%$ of the total agricultural land of Lithuania was occupied by organic farms, indicating the slow process of converting and convincing farmers to move from a traditional to an organic system. However, the Birzu district was characterised by a more rapid increase in the number of organic farms, accounting for more than $10 \%$ of organic farms in the country. This is mainly attributed to the Tatula programme's impact.

The aforementioned slow pace began to change after the entry of Lithuania into the EU in 2004, which led to an increase in financial support for organic farming. In 2012, already 5.4\% of the country's agricultural land was used for organic farming. Birzu district also experienced rapid growth in organic farming volumes, with organic farms covering $14.4 \%$ of agricultural land during the same year. Although organic farming volumes continue to grow throughout the country even now, Birzu farmers remain amongst the leaders in the country's organic farming. The district has almost three times more intensive use of agriculture land for organic farming in comparison to other districts, on average.

The other type of impact, which can also partially be attributed to the Tatula programme, relates to the development of local agriculture farms in terms of production and farm viability. Constant support to diversify organic farms' products (including an increase in the variety of both raw and processed agriculture products) and established connections between local farmers and customers contributed to family-owned farms' long-term viability. This could not have been achieved in the conventional agricultural market, which is dominated by large businesses. Successful transition to organic farming was conditional on many families maintaining their businesses or even growing from subsistence farming to small businesses, thereby ensuring their financial income. Lasting family traditions and experience in organic farming encouraged some members of young generations to start their own organic farming business, while parents continued working on the old family farm. Moreover, the economic spin-off observed with the increase in organic farms prompted the establishment and local organic food production businesses (e.g., mills), which are closely interlinked with the region's organic farms and partially depend on their supply. All these 
circumstances are crucial to the region maintaining its cultural agriculture business ecosystem, which relies on local human resources and contributes to local socioeconomic development.

\section{Results}

We applied our research to observe and understand the role local family farms have played in the Tatula programme and what could have been the key factors for its success. Based on our interpretation of the data collected, having local family farmers in the programme highlights several important consequences at three levels of analysis.

First, at the family level, business families were able to redirect their entrepreneurial efforts, generational knowledge, and physical resources into a sustainable economic activity. In this sense, the programme facilitated the reinvention of farmers' families and created competitive advantages. Active family participation in the economic activity created a sustainable business model difficult for big corporations to imitate, which are more interested in profit maximisation at the expense of local and environmental conditions. Organic farming, the scale of farms that make it economically sustainable, and family participation are important conditions that implicitly or explicitly have made a generation of family farmers stay in their regions.

Second, at the local community level, the programme incentivised farmers to remain attached to their land, find alternative uses for local resources, and helped them avoid needing to migrate to urban areas. The programme did not use short-term incentives with the promise of fast results; instead, it succeeded by helping socioeconomic actors, such as family firms, find reasons to be embedded in their communities. Even though local family farmers were attached to their communities previously, the programme reinforced and renewed links and increased farmer family retention.

Third, at the national level, the programme helped connect rural and urban areas not only by meeting the supply and demand at a certain point in time and space but also by humanising the whole production system by facilitating physical meetings between producers (also sellers) and customers. This exchange of experience, needs, and expectations on market floors created a long-lasting relationship and mutual understanding. Direct links between producers, sellers, and customers materialise the sustainable economy.

Even though there are positive consequences from involving local family firms (business families) in the programme, family firms, because of their specificities, could also bring unique challenges for the sustainability of the programme. To focus on the local needs and context, changing the situation of existing organic farms requires deeper considerations. Some local organic farms have been in operation for more than 20 years; hence, the problem of farming management succession, that is, the new generation, becomes more prevalent. Although are no statistics, our observations suggest that some successful family-owned organic farms whose founders or successors have died are changing the type of farming and returning to conventional 
methods that rely on synthetic pesticides, herbicides, and fertilisers. On the other hand, some family farms are able to successfully transfer the knowledge of organic farming practices to the second or sometimes even third generation of family members, proving the sustainability of organic production businesses. This observation is relevant to evaluate the programme in the long term and to redesign its future actions. Even though the programme has been successful so far, its sustainable impact is not guaranteed. The family dimension of the business would require addressing several challenges related to ownership and generational management changes.

\section{Discussion and conclusion}

This chapter aimed to explore the micro-foundation of the place-based approach by focusing on family firms when developing and implementing initiatives to boost local socioeconomic development in lagging regions. We argued that family firms, characterised by the embeddedness of family members in the formal and informal institutional contexts, may act as essential nodes in the relational space, accelerating information flows, creating trust, and assimilating knowledge across generations.

Our main conclusion is that the place-based approach used in the Tatula programme was critical in creating incentives for long-lasting impact among local socioeconomic actors such as family farms. The family condition of the business target of the programme was important to its success because business families have several characteristics that leverage and reinforce programme actions, such as farming knowledge across generations, local embeddedness, local social capital, and the intention to stay in the region. The Tatula programme nudged the family entrepreneurial orientation to reconfigure resources and capabilities to give sense to the farmer activities and restore the association with the territory. It is difficult to ascertain if such results could be achieved with non-family farms or multinational firms.

Even though the programme achieved positive results, several risks or challenges have to be addressed in the coming years. One of these is related to the generational and succession issues that any family firm has to overcome. In this particular case, family farmers have to navigate the ownership and management transition from one generation of family members to another. Several questions remain open: Is there any family business member who would like to continue with the farm? Has the current generation prepared for the coming generation to continue the leadership? How should the ownership and family wealth be distributed to guarantee the continuity of the family farm? Is it possible to distribute the family wealth when it is attached to the family firm or economic activity? How can the land be distributed among family members to continue farming? How can those family members that do not want to continue with the main economic activities be compensated? Is there any other alternative to compensate them without destroying necessary resources for farming activities? The future versions 
of the Tatula programme have to deal with these kinds of issues to create sustainable socioeconomic development across generations.

\section{Theoretical and practical contributions}

The exploratory nature of our study could have several implications for theory and practice. First, our findings have theoretical implications for those scholars attempting to explain the role that family firms play in local socioeconomic development. Our results reinforce the model proposed by Basco (2015), that is, the embeddedness of family firms in the relational space is an important characteristic that enhances the quality of proximity, not only in its classical geographical dimension but also in its organisational, institutional, social, and cognitive dimensions. Our results also highlight the importance of family firms for regional processes necessary to activate conditions for local development. For instance, in line with previous studies in Lithuania (Stangej \& Basco, 2017), family firms can trigger entrepreneurial processes by reconfiguring existing local resources, learning process by using and creating new knowledge, information exchange process by disseminating critical information and ideas, and spill-over process by encouraging family members or new actors to extend economic activities. The importance of family firms as economic and social nodes in the local economy has not been clearly understood, and future studies should investigate the micro-foundations of family firms in regional studies.

In addition to theoretical implications, our results also offer some practical recommendations for policymakers, who should pay attention to the soft local resources and processes that may boost or retard regional economic development while framing policies. The most important lesson is that economic actors are not rational in their behaviours and traditional incentives such as relocation of multinational factories through incentives (e.g., tax reliefs) do not necessarily work for all regions. To better understand the geographical, formal, informal, and historical aspects, local communities could help develop a unique solution to reactivate their economies. In this sense, embracing family firms could reinforce actions, leverage resources, and connect past, present, and future local knowledge for sustainable development. Future studies should explore other place-based approach programmes and actions to better understand the connection between family firms (as one socioeconomic actor) and the place-based approach. In this sense, future studies should focus on the micro-foundations of the place-based approach by considering factors, actors, and processes.

\section{References}

Barca, F., McCann, P., \& Rodriguez-Pose, A. (2012). The case for regional development intervention: Place-based versus place-neutral approaches. Journal of Regional Science, 52(1), 134-152.

Basco, R. (2015). Family business and regional development - A theoretical model of regional familiness. Journal of Family Business Strategy, 6(4): 259-271. 
Basco, R. (2017). "Where do you want to take your family firm?" A theoretical and empirical exploratory study of family business goals. Business Research Quarterly, 20, 28-44.

Basco, R., \& Bartkevičiūte, I. (2016). Is there any room for family business into European Union 2020 strategy? Family business and regional public policy. Local Economy, 31(6): 709-732.

BGI Consulting. (2019). The evaluation of the implementation of the operational program for the European Union funds' investments in 2014-2020, specific objective 8.6.1. "Improve local employability and enhance social integration of communities, by making use of relationship among local communities, businesses and local governments". The study was commissioned by the Ministry of the Interior of the Republic of Lithuania.

Boudeville, J.-R. (1966). Problems of Regional Economic Planning. Edinburgh: Edinburgh University Press.

CSIL, Centre for Industrial Studies. (2015). Territorial Agenda 2020 put in practice: Enhancing the efficiency and effectiveness of Cohesion Policy by a place-based approach. The study was commissioned by the European Commission DirectorateGeneral for Regional and Urban Policy.

Felice, E., \& Lepore, A. (2017). State intervention and economic growth in Southern Italy: The rise and fall of the 'Cassa per il Mezzogiorno' (1950-1986). Business History, 59(3), 319-341.

Higgins, B., \& Savoie, D. J. (1988). Regional Economic Development: Essays in Honour of Francois Perroux. London: Routledge.

Lenz, R. (2020): Family firms and their regional ties: A bond made for future? In R. Basco, R. Stough, \& L. Suwala (Eds.), Family Business and Regional Development. London: Routledge.

Pacione, M. (1982). Economic development in the Mezzogiorno. Geography, 67(4), 340-343.

Perroux, F. (1955). Note sur la notion de pole de croissance? Economic Appliqee, 307-320. (Translated as: Perroux, F. (1970) Note on the concept of growth poles. In D. McKee, R. Dean, \& W. Leahy (Eds.), Regional Economics: Theory and Practice (pp. 93-104). New York: The Free Press.

Pike, A., Rodríguez-Pose, A., \& Tomaney, J. (2006). Local and Regional Development. London: Routledge.

Ricotta and Basco. (2020). Family firms in European regions: The role of regional institutions. Entrepreneurship and Regional Development, forthcoming.

Rogerson, C. M., \& Rogerson, J. M. (2010). Local economic development in Africa: Global context and research directions. Development Southern Africa, 27(4), 465-480.

Rodríguez-Pose, A., \& Wilkie, C. (2017). Revamping local and regional development through place-based strategies. Cityscape: A Journal of Policy Development and Research, 19(1), 151-170.

Stangej, O., \& Basco, R. (2017). The entrepreneurial role of families in transitional economies: The case of Lithuania. In A. Sauka \& A. Chepurenko (Eds.), Entrepreneurship in Transition Economies: Diversity, Trends, and Perspectives (pp. 345-365). Cham: Springer International Publishing.

Scott, A., \& Storper, M. (2003). Regions, globalization, development. Regional Studies, 37(6-7), 579-593. 
Storper, M. (1997). The Regional World, Territorial Development in a Global Economy. New York: Guilford Press.

Storper, M. (2011). Why do regions develop and change? The challenge for geography and economics. Journal of Economic Geography, 11, 333-346.

Trigilia, C. (2012). Why the Italian Mezzogiorno did not achieve a sustainable growth: Social capital and political constraints. Cambio. Rivista Sulle Trasformazioni Sociali, 2(4), 137-148.

Vazquez-Barquero, A. (1999). Inward investment and endogenous development. The convergence of the strategies of large firms and territories? Entrepreneurship \& Regional Development, 11(1), 79-93.

Vasquez-Barquero, A. (2010). The New Forces of Development: Territorial Policy for Endogenous Development. Singapore: World Scientific.

Walsh, C. (2012). Territorial agenda of the European Union 2020: Towards an inclusive, smart and sustainable Europe of diverse regions. Planning Theory \& Practice, $13,1-4$. 